\title{
Occupational stressors, risks and health in the seafaring population
}

\author{
ANA SLIŠKOVIĆ and ZVJEZDAN PENEZIĆ
}

\begin{abstract}
Previous studies indicate that the most important stressors in the seafaring population are: long-term separation from home and families; loneliness and social isolation; work-related stressors (high workload and long working hours, low control and work-role conflict), and environmental stressors related to life on board. The seafaring population is also subject to many risks, especially those relating to accidents and injuries, pirate incidents, morbidity from infectious diseases, the limited ability to provide medical aid on board, and an increased risk of cancer. Studies of seafarers' mortality indicate that this population is still characterized by a high risk of fatal accident, diseases that are the results of an unhealthy lifestyle, and also by the high level of suicides in the seafaring population, which could be seen as a reflection of impaired mental health. The physical health of seafarers has been the subject of numerous studies, which have focused mostly on cardiovascular diseases and cancer. On the other hand, the mental health and psychological well-being of seafarers are relatively less well-explored. Finally, the paper gives some guidance for further studies, as well as recommendations for minimizing the negative effects of occupational stressors and risks on seafarers' health.
\end{abstract}

Key words: seafarers, occupational stressors, mortality, physical health, well-being

According to the latest assessment of the global supply and demand for seafarers (BIMCO/ISF, 2010), worldwide supply of seafarers is estimated to be 1371000 , i.e., 624 000 officers and 747000 ratings or crew members. BIMCO/ISF (2010) show continued positive trends in both demand and supply of seafarers despite the global economic downturn, but it also reflects significant increases in seafarers from some countries, particularly China, India and the Philippines, as well as in several European countries. The current main suppliers of officers and ratings are OECD countries $(29.4 \%$ of officers and $19.2 \%$ of ratings in global supply) and Far East (19.2\% of officers and $36.7 \%$ of ratings in global supply). Eastern Europe, with $20.3 \%$ of officers and $14.6 \%$ of ratings, becomes also labour supplying region of increasing importance. According to BICMO/ISF (2010) the supply of officers worldwide is lower than the demand by $2 \%$. Analysis of international seafarers' market shows that over recent decades there has been a decline in number of seafarers from developed countries, and this decline along with a desire to reduce labour unit costs, created increasing demands for seafarers from developing countries,

Ana Slišković, Department of Psychology, University of Zadar, Obala kralja Petra Krešimira IV, 2, 23000 Zadar, Croatia.

E-mail: aslavic@unizd.hr (the address for correspondence);

Zvjezdan Penezić, Department of Psychology, University of Zadar. particularly at junior officers and ratings levels (McLaughlin, 2012).

Described trends show that seafaring has become a less attractive profession in developed countries in recent years (McLaughlin, 2012), what impose challenges in recruitment and retention of seafarers. On the other hand, the health and well-being of seafarers has been dramatically influenced by several factors within the last three decades. These factors include the globalization of the shipping industry, increased automation and mechanization of work on ships, improvements in navigation techniques, reduction in crew numbers, increased uncertainty and short-term contracting of seafarers in commercial fleets, multicultural crewing, and ships operated under flags of convenience (MacLachlan, Kavanagh, \& Kay, 2012). Therefore, the old saying, "A sailor's bread is bread with seven crusts", still illustrates seafaring as a demanding, stressful and high-risk occupation. Seafaring is characterized by specific mental, psychosocial and physical stressors which cannot be compared with jobs ashore (Carotenuto, Molino, Fasanaro, \& Amenta, 2012; Oldenburg, Baur, \& Schlaich, 2010a). There is a large number of stressors, risks and challenges that seafarers face, such as long periods away from home, isolation, long working hours, lack of shore leave, fatigue, high levels of workrelated stress, accidents and maritime disasters, exposure to hazardous substances, communicable diseases, impaired treatment options for cardiovascular diseases, and dangers from piracy (Allen, Wadsworth, \& Smith, 2008; Carotenuto 
et al., 2012; Iversen, 2012; MacLachlan et al., 2012; Oldenburg et al., 2010a). These can lead to consequences for the physical and psychological health of seafarers.

\section{OCCUPATION-RELATED STRESSORS AND RISKS FOR SEAFARERS}

One of the most frequently-cited stressors (i.e., sources of stress) in seafaring is long-term separation from home and family (Carotenuto et al., 2012; Iversen, 2012). Although this stressor is especially evident in the cases of longer contract duration (Oldenburg et al., 2010a), the fact is that all seafarers are by the nature of their work separated from their families. Even under the most favourable employment conditions seafarers spend at least six month of year at sea (Alderton et al., 2004). Stress levels caused by separation from home increase significantly when family members are not well or when contact with the family is difficult (Carotenuto et al., 2012). Being physically away from home and family can bring anxiety related to the illness of loved ones, the sexual fidelity of partner, problematic behaviour of children, family's general well-being and practical household matters (Alderton et al., 2004). Cyberspace communication with the partner is of great importance for peer social support and strengthening of relationships (Tang, 2012). Beside loneliness caused by separation from family, partner or wife and children, seafarers also report social isolation, caused by their characteristic way of life on board, now also additionally aggravated by reduction in crew numbers, short ship-turnaround times and lack of shore leave (Iversen, 2012; MacLachlan et al., 2012). Besides short ship-turnaround times, the reasons for low levels of shore leave are: working, a need for rest, difficulties in simply getting to the dockyard gate from the berthing area, lack of visa or security regulation in the country, and depression (Iversen, 2012). Social isolation in seafarers is a major cause of psychological problems, such as depression, and in particular situations, and in vulnerable individuals, this can lead to suicide (Carotenuto et al., 2012; Iversen, 2012).

Work-related stressors of seafaring include typical sources of work stress which are recognized in many workstress models, such as: the demands of the job (high workload and long working hours); the level of control seafarers have over their work; the support received from management and colleagues; relationships at work; the seafarers' role in the organization; change and change management; and job security (especially for non-rated seafarers who are employed on contract; Iversen, 2012). These stressors lead to typical symptoms of stress, such as insomnia, loss of concentration, anxiety, frustration, anger, headaches, heart disease, and less productivity in general, but they can also lead to burnout and chronic responsibility syndrome. Chronic responsibility syndrome is defined as a kind of burnout where people become mentally and physically exhausted from high workload caused by individual perception that no one but them can do the work (Iversen, 2012). Regarding working hours, the results of an international study which included 6461 seafarers from 11 countries showed that most seafarers worked every day of the week, for 67-70 h a week on average, during periods of 2.5-8.5 months at sea (Jensen et al., 2006). In addition, comparison of seafarers with non-seafarers of matched ages show a significant difference in the level of control between them (Lodde et al., 2008). That is, assessments of Karasek's decision-latitude dimension (1979) were at much lower levels for seafarers than for non-seafarers. The results also showed that $17 \%$ of seafarers (compared to zero percent of non-seafarers) were ranked in the category of heavy strain/low decision latitude, which is regarded by Karasek as a high risk of stress, and that $33 \%$ of seafarers reached a score which indicated psychic stress according to Langner's Total Health Test. One of the workrelated stressors which were highly elevated is role conflict (Rydstedt \& Lundh, 2010). Role conflict appears where conflicting requirements by other actors and interested parties in the shipping operation are directed towards the individual seafarer. It is particularly characteristic of mid-level managers "who are supposed [to] live up to their professional standards in shipping and at the same [time] operate the ship with reduced crew numbers and high speed, so as to satisfy the requirements for profitability" (Rydstedt \& Lundh, 2010, p.174). The authors assumed that the rapid technological and organizational change and increased pressure for economic profitability that characterize the shipping industry have attenuated this source of stress. In the context of working stressors on board, one of the major issues is fatigue. Fatigue in seafarers is regarded as a consequence of work stress, high job demands, insufficient crew members, long working hours, and disturbed circadian rhythms imposed by working patterns and shift schedules, sleep deprivation and compromised safety standards (Allen et al., 2008; Carotenuto et al., 2012; Hystad, Saus, Sætrevik, \& Eid, 2013; Smith, Allen, \& Wadsworth, 2006; Oldenburg et al., 2010a; Wadsworth, Allen, McNamara, \& Smith, 2008; Wadsworth, Allen, Wellens, McNamara, \& Smith, 2006). Many maritime studies have focused on fatigue, since it is considered the most important risk factor for maritime accidents with severe, life-threatening environmental and economic consequences, as well as for the impairment of seafarers' health and well-being (Carotenuto et al., 2012; Iversen, 2012; Oldenburg et al., 2010a). Unfortunately, fatigue is more prevalent in the seafaring world than scientists are currently able or prepared to measure (Allen et al., 2008). Authors in this field warn of a concerning number of under-recorded working hours in seafarers (Smith et al., 2006). Sleep disturbance is a common stressor shared by seafarers, especially by seafarers sailing aboard ships rapidly crossing several time zones (Carotenuto et al., 2012). Regarding comparisons between fixed and rotating watch schedules, results of experimental studies (e.g., Arulanandam \& Chan Chung Tsing, 2009) show that fixed watch schedules allow better 
acclimatization of sleep patterns, thus minimizing fatigue and increasing operational alertness. Disturbance of circadian rhythms imposed by shift work, especially night work, is recognized as an important factor in the development of sleep disturbance, as well as serious illnesses such as gastrointestinal and cardiovascular diseases (Slišković, 2010). Results of studies in seafarers confirm a strong independent association between longer-term fatigue and physical- and mental-health outcome measures (Smith et al., 2006; Wadsworth et al., 2008; Wadsworth et al., 2006). Data also show that measuring seafarers' fatigue on waking may be a more sensitive measure of emerging cumulative fatigue, which could relate to occupational performance, accident risk, and perhaps longer-term well-being (Wadsworth et al., 2006).

In addition to stressors relating to the characteristic way of life (e.g., separation from families) and specific work stressors and related fatigue, seafarers are continuously exposed to environmental stressors on board, such as ship motion, noise and vibration, which can significantly impact the recreational value of leisure and sleeping times (Oldenburg et al., 2010a). An additional environmental stressor for engine personnel is the heat in the workplace (Rengamani \& Murugan, 2012). Life on board brings with it additional stressors, primarily those related to the deprivation of physical and psycho-social needs. During the stay on board, seafarers have limited influence on quality and quantity of food (Oldenburg, Harth, \& Jensen, 2013), and their nutrition issue is even more pronounced in multi-ethnic crews with different dietary habits. Limited opportunities for recreation are regarded as an important source of stress, since the oftenobserved lack of leisure-time facilities (e.g., fitness rooms or social events) impairs seafarers' physical, psychological and social well-being (Carotenuto et al., 2012; Oldenburg et al., 2010a). Disturbed sexual life on board is also associated with the occurrence of psycho-emotional stress in seafarers (Oldenburg et al., 2010a). Interpersonal relationships are generally recognized as the one of the occupational stressor (Cartwright \& Cooper, 1996), which includes conflicts with the behaviour of supervisors, colleagues, subordinates and management policies. Considering the frequent changes in working teams on board and working in the multinational and multicultural environment in the seafaring sector, interpersonal relationships may pose a specific challenge for seafarers. Multinational crews are recognized as a specific stressor, too (Oldenburg et al., 2010a). Since crews consist not only of many different nationalities but also of different religious and cultural backgrounds, different needs, values and expectations may lead to communication problems, conflicts, abuse, racism and isolation (Carotenuto et al., 2012; Oldenburg et al., 2010a; Iversen, 2012). Adequate English language skills among crew members are prerequisite not only for work, but also for the socialization on board (Sampson \& Zhao, 2003). Finally, some seafarers report exploitation and abuse (Iversen, 2012). This is evident in those seafarers who work in a substandard sector of mer- chant shipping (ships defective in structure and equipment, and those with low wages and poor working conditions). Hayashi (2001) warned that the entire maritime industry suffers from practices which disregard generally accepted standards.

Seafarers also report one special source of stress, known as criminalization of seafarers. It is a term used to describe the treatment of maritime incidents (for example oil pollution incidents, maritime accidents beyond their control; maritime accidents where there has been some negligence, regardless of the fact that such negligence is not considered criminal in the maritime industry) as 'true crimes'. It is also used as a blanket term to describe the denial of procedural and human rights in the investigation and prosecution of those incidents (Iversen, 2012).

Besides the above stressors, seafaring has many risks. Although disaster and accident rates have been reduced over the course of time, despite recent improvements in occupational safety standards on board, seafaring is still a high-risk occupation. Statistics produced by the International Maritime Organization reveal that $80 \%$ of accidents aboard cargo ships are caused by the human factor (Oldenburg, et al., 2010a). The main causes of fatal work-related injuries are rough weather, insufficient awareness of safety, lack of use of personal protective devices, and inexperience (Oldenburg et al., 2010a). Data show that, despite an increase in the application of risk prevention policies in Spain, there are important legal gaps in maritime sector regulations which can lead to negligence over seafarers' safety and health (Rodríguez, Portela, \& Carrera, 2011). Further, incidence of piracy has been rising since the mid-1990s; here, the most-affected areas are the South China Sea, the coasts of East and West Africa and the Indian Ocean (Oldenburg et al., 2010a). Increased violence, abuse and threats to hostages and longer hostage periods are also reported (Iversen, 2012).

The characteristic way of life on board leads to risk from communicable diseases. Crew members with different susceptibilities to infection share living quarters and common food and water supplies, as well as sanitation and airconditioning systems (Oldenburg et al., 2010a). Therefore, on-board hygiene is one of the main causes of the spread of communicable diseases. The results of a study on crew members and on-shore personnel of one Italian firm show that seafarers should be targeted by specific informative campaigns about health risks related to contracting communicable diseases (Grappasonni, Paci, Mazzucchi, De Longis, \& Amenta, 2012).

One of the special risks in seafaring is the limited ability to provide medical aid on board, which is most pronounced in cases of heart failure. Impaired treatment of cardiovascular diseases at sea is due to the facts that medical care on board is administered by a medical health officer who is not a medical professional, that treatment options are generally 
limited on board, and that evacuation ashore is often problematic and delayed (Oldenburg et al., 2010a; Oldenburg, Baur, \& Schlaich, 2010b).

Finally, an elevated risk of occupational cancer, which is reported as one of the risks in seafaring, is probably partially caused by lifestyle factors such as alcohol, smoking and diet. However, exposure to UV light from the sun, handling toxic cargoes and a variety of possibly harmful exposures in the engine room cannot be ignored (Oldenburg et al., 2010a).

\section{MORTALITY IN SEAFARERS}

The need for serious focus on preventing the negative effects of occupational stressors and risks in seafarers is additionally evident from mortality studies in the seafaring population. The results of a study which involved 24132 Danish seafarers (Hansen \& Pedersen, 1996) have shown that merchant seafarers have a higher mortality than the general population. To be precise, the standardized mortality ratio was 1.43 (95\% CI: $1.33-1.54)$ from all causes and 3.05 (95\% CI: 2.62-3.52) from accidents. Despite a very high risk of fatal accidents in the workplace, these accidents could only explain a proportion of the observed excess mortality. Accidents ashore (outside the workplace) and diseases related to lifestyle factors such as drinking and smoking made a major contribution to the observed excess mortality. The results of mortality studies in seafarers can generally be divided into three categories: (a) mortality from accidents, (b) mortality from diseases related to lifestyle, and (c) suicide mortality.

\section{Accidents related mortality in seafarers}

Further research on Danish seafarers (Hansen, Nielsen, \& Frydenberg, 2002) focused on occupational accidents aboard merchant ships in international trade (time period 1993-1997). Among a total number of 1993 accidents, 209 accidents resulted in permanent disability of $5 \%$ or more, and 27 were fatal. The most significant risk factors were: age, change of ship, first period aboard a particular ship, and walking from one place to another on board. A longitudinal population based study of seafarers employed in British merchant shipping from 1976 to 2002 (Roberts \& Marlow, 2005), which was based on official mortality files, has shown that the mortality rate for the 530 fatal accidents that occurred at the workplace in the observed time period (46.6 per 100,000 seafarer-years) was 27.8 times as high as in the general workforce in Great Britain during the same time period. To be precise, of 835 traumatic work-related deaths, 564 were caused by accidents, 55 by suicide, 17 by homicide, and 14 by drug or alcohol poisoning. The circumstances in which the other 185 deaths occurred, including 178 seafarers who disappeared at sea or were found drowned, were undetermined. The authors conclude that, despite improvements in health and safety that have led to substantial reductions in fatal accident rates in UK merchant shipping throughout most of the last 90 years, seafaring has remained a hazardous occupation (Roberts \& Marlow, 2005). Actually, the data show that the relative risk of an accident in UK shipping, compared with the general British workforce, was similar in 2001 to that in 1961 (Roberts, 2008). Since shipping accidents remain a major concern in the modern shipping industry, contemporary studies deal with analysis of causes of different classes of accidents and collisions (Chauvin, Lardjane, More, Clostermann, \& Langard, 2013), prediction of mortality count based on influencing factors, such as type and place of accident, weather and darkness conditions (Weng \& Yang, 2015), and differences between nationalities in the rate of accidents which can be attributed to differences in safety culture (Ádám, Rasmussen, Pedersen, \& Jepsen, 2014).

\section{Disease-related mortality in seafarers}

Regarding mortality from gastrointestinal diseases and from alcoholism, mortality data on seafarers employed in British merchant shipping from 1939 to 2002 (Roberts, 2005) show sharp reductions. These results contrast with increases among the general British population, and are largely due to the 'flagging-out' of most British deep-sea ships, and consequent reductions in long voyages, as well as reductions in alcohol consumption among seafarers at work. Largely because of the healthy worker effect, seafarers were usually at increased risk only from particularly acute diseases.

Lower work-related mortality from cardiovascular diseases (CVD) and ischemic heart disease among seafarers employed in British shipping than in the corresponding general population ( $\mathrm{SMRs}=0.35$ to 0.46$)$ is also explained by a healthy worker effect among the seafarers (Roberts \& Jaremin, 2010). At the same time, mortality risk from CVD among British seafarers ashore in Britain increased, which is at least partially caused by seafarers being discharged ashore from active service because of sickness or disability, including CVD morbidity. Results from the same study showed an increase in mortality risk from CVD among the crews of North Sea offshore ships, which may reflect particular work-related hazards in this sector.

\section{Suicide mortality in seafarers}

The data on suicides prove that the mental health of seafarers in many cases continues to be very poor and often fatal (Iversen, 2012). While the figure for suicide among total deaths in the general population ranges from 1.2 to $2 \%$, suicides by seafarers are much more common. Seafarers' death statistics based on 20 reports published in the years 
from 1960 to 2009 show that, of a total of 17026 seafarer deaths, 1011 (i.e., 5.9\%) were by suicide (Iversen, 2012). It should be noted, however, that this analysis included a very long time period, as well as crews of different nationalities.

Analysis of suicides among seafarers in UK merchant shipping (Roberts, Jaremin, Chalasani, \& Rodgers, 2009) show that the suicide rate among seafarers was substantially higher than the overall suicide rate in the general British population from 1919 to the 1970s; but, following reductions in suicide mortality among seafarers, it has become more comparable since. These drops are explained by reductions over time in long intercontinental voyages and changes in seafarers' lifestyles over time. The results of this study additionally show that suicide rates among seafarers in UK merchant shipping were higher for ranks below officers and for older seafarers, and higher for Asian seafarers than for British seafarers (Roberts et al., 2009). The data also indicate that suicide rates among seafarers in UK merchant shipping were typically lower than those in Asian and Scandinavian merchant fleets.

The results of a mortality study among Polish seafarers and deep-sea fishermen have shown that the incidence of suicides among the observed sample during work at sea was significantly higher than suicides among the age-comparable male population of the country (Szymanska, Jaremin, \& Rosik, 2006). The risk is greatest for seafarers aged 30-39 years, with a period of service from 10 to 24 years, working as ratings, with known or concealed alcohol addiction and/or family problems or insufficient identification with the group.

\section{HEALTH OF SEAFARERS}

\section{Physical health of seafarers and lifestyle factors}

According to a review of publications in the journal International Maritime Health from 2000 to 2010 (MacLachlan et al., 2012), among physical health problems in seafarers, most papers focused on cardiovascular disease, heart attack, diabetes, and lifestyle factors which contribute to these diseases.

Although acute cardiovascular diseases are the main cause of death in industrialized countries (both at sea and on land), the results of the study show that, after taking into consideration the healthy worker effect of seafarers, cardiac risk factors are shown to occur slightly more frequently in seafarers than in the general population (Oldenburg et al., 2010b). Results of research on cardiovascular and coronary diseases in seafarers on vessels under the German flag show that, in spite of the seafarers' regular medical surveillance examination, their CHD risk was similar to that of a reference population working ashore (Oldenburg, Jensen, Latza, \& Baur, 2007; Oldenburg, Jensen, Latza, \& Baur, 2010).
Since seafarers may be exposed to engine exhaust, various oil products and many carcinogenic chemicals, some studies have focused on cancer risk. The results of a study which aimed to investigate the possible work-related reasons for the increased incidence of many cancers among seafarers who worked on Finnish ships for any time during the period 1960-1980 (Saarni, Pentti, \& Pukkala, 2002) show that occupational exposure of deck crews on tankers adds to their risk of renal cancer, leukaemia and possibly lymphoma. On the other hand, engine crews have an asbestos-related risk of mesothelioma, and engine-room conditions also seem to increase the risk of lung cancer. The results of research conducted on all Danish seafarers during 1986-1999 who were followed up for cancer until the end of 2002 have shown that Danish seafarers, especially men, face an increased overall cancer risk - in particular, risk of lung cancer and other tobacco-associated cancers (Kaerlev, Hansen, Hansen, \& Nielsen, 2005).

Regarding slightly elevated risk for cardiovascular disease risk in seafarers, Oldenburg (2014) allocated three influenceable risk factors: the ship specific stress situation (originated from specific occupational psychosocial stressors), the malnutrition (unbalanced and highfat diet) and the lack of exercises on board. Data generally show that lifestyle factors explain a large proportion of mortality and disease in seafarers. Comparison of sea captains and marine chief engineers with a group of ordinarily employed men (matched with the seafarers for age, ethnic origin and level of education) has shown that certain behavioural risk factors were more dominant among the seafarers than among the control group. These include smoking level, alcohol consumption and lack of leisure-time physical activity (Carel, Carmil, \& Keinan, 1990). Analysis of national data for England and Wales indicates that seafarers are among the groups of occupations with the highest mortality from alcohol-related diseases and injuries (Coggon, Harris, Brown, Rice, \& Palmer, 2010). The results of a stratified survey of French seafarers (Fort, Massardier-Pilonchery, \& Bergeret, 2009) confirmed that alcohol and nicotine consumption is a major public health issue in seafarers. Approximately $44 \%$ of their sample were current smokers, and more than $11 \%$ drank alcohol every day. Review study (Pougnet et al., 2014) which focused on consumption of addictive substances showed higher prevalence of tobacco and alcohol consumption in seafarers compared to general population. According to this review which was based on international publications, $63.1 \%$ of seafarers smoked, while $14.5 \%$ were hazardous drinkers (according to the WHO definition). Besides smoking and alcohol consumption, one of the factors in lifestylerelated diseases that dominate among seafarers is obesity. Overweight was found, to a statistically significant extent, to be represented more highly in seafarers than a reference group ashore (Hoeyer \& Hansen, 2005), and this can influence seafarers' health and shipboard safety. Data also show that the best predictor of work ability in seafarers was the 
interaction between body-mass index and age, where the adverse effect of high body-mass index was greater in older seafarers (Bridger \& Bennett, 2011). Study results show that obesity among seafarers is favoured by compulsive eating disorder, night eating disorder and emotional eating disorder, and that eating is most frequently a reaction to stress or boredom (Jeżewska, Babicz-Zielińska, Leszczyńska, \& Grubman, 2009).

It can be generally concluded that besides working conditions, unhealthy life style of seafarers also significantly contribute to negative health outcomes. Further research in this area should focus on questions such as: Do people of specific traits and/or life styles incline more to this occupation? and Do the working conditions in seafaring encourage unhealthy life styles?

\section{Psychological well-being and mental health of seafarers}

The above-mentioned review (MacLachlan et al., 2012) showed that the category psychological functioning and health had a relatively small number of papers. Papers relating to stress, fatigue, alertness levels and psychological issues such as depression and general psychological wellbeing featured most prominently in this category. It can be said that the area of psychological well-being and mental health has been relatively neglected in previous studies in comparison to studies which focused on physical health. For example, in a paper titled "Mapping the knowledge base for maritime health", written on 37 pages, psychological aspects of health are almost totally ignored (Carter, 2011). Respecting the definition of health given by the World Health Organization, where health is defined as "a state of complete physical, mental and social well-being and not merely the absence of disease or infirmity", scientists and practitioners in the area of seafarers' health need to give greater emphasis on psychological and mental aspects of health, especially regarding the numerous mental and psychosocial stressors that seafarers can face.

Therefore, studies that focused on psychological wellbeing (e.g., Carotenuto et al., 2013), quality of life (e.g., Juozulynas, Sąlyga, Malakauskienè, \& Lukšienè, 2007) and burn-out syndrome (e.g., Oldenburg, Jensen, \& Wegner, 2012) are encouraged, especially those which aim to determine role of working conditions in the well-being of seafarers. For example, Oldenburg et al. (2012) showed that emotional exhaustion in seafarers is associated with a perception of enough sleep on board, lack of care provided by their superiors and/or the shipping company, with high responsibility for work organisation (for senior members of crew) and with social problems due to the long periods of separation from their families.

Since job satisfaction and intent to leave are considered reliable indicators of work-related well-being, one survey study focused on these variables (Nielsen, Bergheim, \& Eid, 2013). The results of this study, conducted on 817 seafarers working on vessels belonging to two large Norwegian shipping companies, show that job satisfaction and intent to leave among seafarers are related to physical and psychosocial factors in the working environment, and especially safety perceptions, job demands and team cohesion. The results of a study on Danish seafarers (Haka, Borch, Jensen, \& Leppin, 2011) confirmed that the main motivating and demotivating factors are related to psychosocial factors rather than organizational or structural factors. The work motivators which were identified in this study include duration of home leave, level of responsibility and level of challenge, while the main demotivating factors that were identified were being away from home, the shipping company's HRM, and regulatory requirements.

\section{INDIVIDUAL DIFFERENCES IN HEALTH AND WELL-BEING AMONG SEAFARERS}

In view of the various jobs that exist on board, as well as various nationalities, different contract durations of onboard stay and different types of employment contracts, the seafaring population cannot be regarded as a whole. Results of an international study of seafarers (Jensen et al., 2006) have shown that self-rated health generally declined significantly with age, and it varied by country. Obvious explanations of national differences can be found in the fact that seafarers from South-East Asian countries spent longer periods at sea, and had lower numbers of officers and older seafarers than is found among seafarers from western countries. According to that fact is a result of study conducted by Borovnik (2011) who warned on particular health risk for seafarers from developing Pacific countries because of their long contracts on board. The ageing of the workforce is particularly important within the whole of the transportation industry (Popkin, Morrow, Di Domenico, \& Howarth, 2008). Regarding seafarers, results (Rydstedt \& Lundh, 2012) suggest that rapid technological and organizational development in the shipping industry may be associated with increased mental strain for the older engine-room officers. Data from a study of Lithuanian seafarers (Juozulynas et al., 2007) have confirmed age differences in the physical and psychological health-related quality of life (QOL). These results show that physical QOL is best among the youngest seafarers (20-24 years old), while psychological QOL is best among seafarers aged 20-24 and 25-34 years. Obtained age differences are in accordance to previous findings of quality of life in general population (e.g., Diener, 1984; Skevington, Lotfy, \& O’Connell, 2004).

Years of service is also an important variable. Although seafarers' health declines with age (Jensen et al., 2006), the experience which is obtained with years of service could minimize the effects of work-related stressors. The results of one study showed that students, during their training period 
on merchant ships, perceive the job as highly stressing compared to the group of merchant marine officers (Jeżewska, Leszczynska, \& Jaremin, 2006).

The results of the above-mentioned study of Lithuanian seafarers (Juozulynas et al., 2007) also show differences by profession, where health-related quality of life is best among commanding group members. The physical dimension of QOL is worst among engineer ship service members, while psychological QOL is worst among ship auxiliary service seafarers. Study done by Carotenuto et al. (2013) also showed differences in some aspects of psychological wellbeing between seafarers of different categories. Obtained results (higher levels of anxiety and self-control among deck and engine officers compared to the crew) supported the view that management responsibilities are related to higher levels of stress. A study on a sample of Danish seafarers has shown differences in the motivational profiles of officers and non-officers (Haka et al., 2011). All these results show the importance of considering the different characteristics of the various jobs on board since they involve coping with different stressors. While non-officers stay on board for considerable longer periods compared to officers, officers complain more frequently of a time pressure and report higher number of working hours compared to non-officers (Oldenburg, Jensen, Latza, \& Baur, 2009).

\section{SUGGESTIONS FOR FURTHER STUDIES}

In spite of relatively great number of research on stressors and health in seafarers, there is a lack of systematic comprehensive investigation of the complex and multivariate process of occupational stress in seafaring. Therefore, the main suggestion is implementation of an ecologically valid and theoretically rich transactional perspective into the research field (Cooper, Dewe, \& O'Driscoll, 2001; Cox \& Mackay, 1981; Lazarus, 1990). The transactional perspective on occupational stress is focused on three elements: (a) the sources of stress, i.e., stressors, (b) the consequences for the individual and the organization, and (c) individual differences in personality and behaviour (i.e., moderators and mediators). The process of stress depends on the perception of the situation or the assessment of the stressfulness of situations. Stress reaction occurs when an individual determines that the intensity of the stressors overcomes his ability to cope. Considering three main elements of occupational stress process suggestions for further research may be divided to several main points.

Although main stressors in seafarers are already recognized in many studies, there is a lack of accepted instrument for measurement of objective presence and/or perception of different stressors on board, so further effort should be put in development of reliable and valid instruments. Development and validation of such an instrument would allow comparability of results from different studies. A new instrument should incorporate some important work characteristics (e.g., type of vessel, compliance of work contract duration, opportunities for recreation on board, possibilities for shore leave, quality of Internet access on board, etc.) which have been neglected in previous research.

Regarding consequences of occupational stress on seafarers, one of the big issues for further studies to take into consideration is the fact that many studies of seafarers rely on subjective assessments of stress and health. The flaw in these studies is that examinations are conducted on land, not during work at sea. Some authors, in contrast, recommend objective measures, such as monitoring basic physiological parameters on board (Leszczynska, Ježewska, \& Jaremin, 2007). Furthermore, since occupational stress is a dynamic, multifaceted process, measurement of stressors and strains at one single time point do not have the capacity to capture this process. Therefore, longitudinal research is needed to examine effects of stressors on physical health and wellbeing of seafarers. The control of different demographic and health-life style characteristics is of crucial importance here.

Finally, previous studies were primarily focused on the effects of stressors in seafaring on health and well-being of seafarers (individual level), so the consequences on organisational level still have to be investigated. Further studies in this direction (analysis of costs of stress in seafaring) could have practical implications for retention of seafarers in developed countries.

There is a great number of individual and organisational characteristics which may have a moderator or mediator role in the relationship of stressors and stress outcomes in seafaring. Although earlier studies show the significant role of some socio-demographic and work characteristics in the experience of stress, physical health and well-being, many important characteristics are relatively neglected in the field. Personality traits (e.g., anxiety as a trait, neuroticism, negative affectivity, resilience, work locus of control, personal hardiness etc.), as well as strategies for coping with stress, play a significant role in relations between stressors stress outcomes and should be included in further studies on seafarers' health, and especially on seafarers' mental health and psychological well-being. One of the important research questions for further studies is the use of different coping strategies in dealing with different occupational stressors in seafaring. This line of research could differentiate adaptive and maladaptive coping techniques in seafarers and provide practical implications for interventions. The social support in dealing with occupational stress (Karasek \& Theorell, 1990) also deserves special attention in further studies of stress in seafarers. A special focus should be given to the social support from superiors, i.e., identification of supportive and unsupportive behaviours of supervisors which can lead to or decrease occupational stress in seafaring. This could give important insights for training of managers of shipping companies and senior officers. In short, next studies in 
the area should investigate contribution of working conditions in seafaring to explanation of health outcomes while controlling all important individual characteristics, such as personality traits, life styles, coping, perceived support, etc.

At the end, seafarers' families are also affected by some hazardous characteristics of seafaring occupation, which makes the absolute number of target population much larger. In spite of the fact that separation from partner and family is still one of the most important stressors for seafarers, a relatively small number of studies have focused on the effects of separation on seafarers' spouses and families, which is especially important in cases of longer contract duration (Thomas, Sampson, \& Zhao, 2003). The results of some studies (e.g., Parkes, Carnell, \& Farmer, 2005; Ulven, Omdal, Herløvnielsen, Irgens, \& Dahl, 2007) suggest a favourable impression of the adaptation and satisfaction of offshore and seafarers' families, tolerance of the husband's absence, quality of marital relationships and subjective evaluation of one's own health and mental well-being, but the fact is that the length of separation in these studies ranged from two to at most six weeks. The impact of seafaring on families may be reduced by different measures (e.g., shorter trips, improved access to the internet; Thomas et al., 2003) what could in turn lead to better retention of trained seafarers who might otherwise leave the sea or be subject to stress-related illnesses.

\section{RECOMMENDATIONS FOR THE SEAFARING INDUSTRY}

While some demanding aspects of seafaring - such as the inability of employees to leave the worksite, extreme weather conditions, separation from home, and motion of the workplace - are unchangeable, some other physical and psychosocial factors are able to be modified and adjusted (Nielsen et al., 2013). Besides moral care for the employees' health and well-being, the economic cost of impairment to seafarers' health can be very high for the ship owner.

Regarding intervention strategies for optimizing seafarers' health and well-being, it has to be said that some countries, such as the UK and Australia, have valuable projects relating to the mental health of seafarers (Iversen, 2012). However, their main activities (printed booklets and leaflets about methods of stress reduction, recognition of signs of depression, a 24/7 help hotline, etc.) are directed at the seafarers. As such, they can be regarded only as tertiary (dealing with stress outcomes) or in some cases secondary measures of intervention (help in coping with stressors). Still, since many seafarers are reluctant to seek medical and psychological help because of rigorous health requirements at the competitive job market (Iversen, 2012), these measures which raise awareness and help in coping with stressors in seafarers are of great importance. Yet, the main intervention strategies in reducing stress and diminishing the occupational health risk among seafarers should focus on reducing the main occupational stressors and risks (primary measures). On the basis of the main stressors reviewed in this paper, the main primary interventions in seafaring should include: reduction in long separations from families (i.e., shorter durations of stay on board), minimizing fatigue (through reduction of long working hours, increased number of crew and unbroken periods of rest and sleep), improvements in quality of life on board (improvements in telecommunications, nutrition and recreational opportunities, as well as the promotion of social events on board), and educations on healthy life style. Although communication and family life among seafarers are today very favourable compared to former times, which were characterized by year-long separations, short unpaid holidays and communication by letter (Hagmark, 2003), free and unlimited Internet access on board is still just an aspiration for many seafarers. Regarding risks in seafaring, the main primary interventions should be directed at optimizing conditions of hygiene and medical care on board, and prevention of work-related hazards arising from unsafe practices and toxic substances. Some authors (Oldenburg et al., 2010a) note that first-aid education of crews must be improved. Namely, worse outcome of cardiac events on ships compared to ashore is often caused by delayed effective cardio-pulmonary resuscitation (Oldenburg, 2014).

\section{CONCLUSION}

Considering the studies reviewed, which portray seafaring as a stressful and high-risk occupation with a great number of possible negative influences on health and wellbeing, it is important for shipping owners, unions and international regulatory bodies to direct attention to primary intervention strategies, i.e., reduction and minimization of occupational stressors and risks. Although above mentioned measures have certain financial costs, the benefits from the improved retention of seafarers and the avoidance of accidents, injuries and stress-related illnesses, are greater and more important - both for the seafaring industry and for seafarers and their families.

\section{REFERENCES}

Ádám, B., Rasmussen, H. B., Pedersen, R. N. F., \& Jepsen, J. R. (2014). Occupational accidents in the Danish merchant fleet and the nationality of seafarers. Journal of Occupational Medicine and Toxicology, 9, 1-8.

Alderton, T., Bloor, M., Kahveci, E., Lane, T., Sampson, H., Thomas, M.,... Zhao, M. (2004). The Global Seafarer: Living and Working Conditions in a Globalized Industry. Geneva: International Labour Organization.

Allen, P., Wadsworth. E., \& Smith, A. (2008). Seafarers' fatigue: A review of the recent literature. International Maritime Health, 59(1-4), 81-92. 
Arulanandam, S., \& Chan Chung Tsing, G. (2009). Comparison of alertness levels in ship crew. An experiment on rotating versus fixed watch schedules. International Maritime Health, 60(1-2), 6-9.

BIMCO/ISF (2010). BIMCO/ISF manpower update: The worldwide demand for and supply of seafarers. Dalian Maritime University and Institute for Employment Research, University of Warwick.

Borovnik, M. (2011). Occupational health and safety of merchant seafarers from Kiribati and Tuvalu. Asia Pacific Viewpoint, 52, 333-346.

Bridger, R. S., \& Bennett, A. I. (2011). Age and BMI interact to determine work ability in seafarers. Occupational Medicine, 61(3), 157-162.

Carel, R. S., Carmil, D., \& Keinan, G. (1990). Occupational stress and well-being: Do seafarers harbor more health problems than people on the shore? Israel Journal of Medical Science, 26, 619-624.

Carotenuto, A., Fasanaro, A. M., Molino, I., Sibilio, F., Saturnino, A., Traini, E., \& Amenta, F. (2013). The Psychological General Well-Being Index (PGWBI) for assessing stress of seafarers on board merchant ships. International Maritime Health, 64(4), 215-220.

Carotenuto, A., Molino, I., Fasanaro, A. M., \& Amenta, F. (2012). Psychological stress in seafarers: a review. International Maritime Health, 63(4), 188-194.

Carter, T. (2011). Mapping the knowledge base for maritime health. International Maritime Health, 62(4), 209-246.

Cartwright, S., \& Cooper, C. L. (1996). Coping in occupational settings. In M. Zeidner \& N. S. Endler (Eds.), Handbook of coping: Theory, research, applications (pp. 202-220). Chichester: John Wiley and Sons.

Chauvin, C., Lardjane, S., Morel, G., Clostermann, J.-P., \& Langard, B. (2013). Human and organisational factors in maritime accidents: Analysis of collisions at sea using the HFACS. Accident Analysis \& Prevention, 59, $26-37$.

Coggon, D., Harris, E. C., Brown, T., Rice, S., \& Palmer, K. T. (2010). Occupation and mortality related to alcohol, drugs and sexual habits. Occupational Medicine, 60(5), 348-353.

Cooper, C. L., Dewe, P. J., O’Driscoll, M. P. (2001). Organizational stress $-A$ review and critique of theory, research and applications. Thousand Oaks, CA: Sage Publications.

Cox, T., \& Mackay, C. J. (1981). A transactional approach to occupational stress. In E. N. Corlett \& J. Richardson (Eds.), Stress, work design and productivity (pp. 91114). Chichester: Wiley.

Diener, E. (1984). Subjective well-being. Psychological Bulletin, 95, 542-575.
Fort, E., Massardier-Pilonchery, A., \& Bergeret, A. (2009). Alcohol and nicotine dependence in French seafarers. International Maritime Health, 60(1-2), 18-28.

Grappasonni, I., Paci, P., Mazzucchi, F., De Longis, S., \& Amenta, F. (2012) Awareness of health risks at the workplace and of risks of contracting communicable diseases including those related to food hygiene, among seafarers. International Maritime Health, 63(1), 24-31.

Hagmark, H. (2003). Women in maritime communities: A socio-historical study of continuity and change in the domestic lives of seafarers' wives in the Aland Islands, from 1930 into the New Millennium (Unpublished doctoral thesis). University of Hull. Retrieved from http:// core.kmi.open.ac.uk/download/pdf/5222524.pdf

Haka, M., Borch, D. F., Jensen, C., \& Leppin, A. (2011). Should I stay or should I go? Motivational profiles of Danish seafaring officers and non-officers. International Maritime Health, 62, 20-30.

Hansen, H. L., Nielsen, D., \& Frydenberg, M. (2002). Occupational accidents aboard merchant ships. Occupational and Environmental Medicine, 59(2), 85-91.

Hansen, H. L., \& Pedersen, G. (1996). Influence of Occupational Accidents and Deaths Related to Lifestyle on Mortality among Merchant Seafarers. International Journal of Epidemiology, 25(6), 1237-1243.

Hayashi, M. (2001). Toward the Elimination of Substandard Shipping: The Report of the International Commission on Shipping. The International Journal of Marine and Coastal Law, 16(3), 501-513.

Hoeyer, J. L., \& Hansen, H. L. (2005). Obesity among Danish seafarers. International Maritime Health, 56(1-4), 48-55.

Hystad, S. W., Saus, E. R., Sætrevik, B., \& Eid, J. (2013). Fatigue in seafarers working in the offshore oil and gas re-supply industry: Effects of safety climate, psychosocial work environment and shift arrangement. International Maritime Health, 64(2), 72-79.

Iversen, R. T. B. (2012). The mental health of seafarers. International Maritime Health, 63(2), 78-89.

Jensen, O. C., Sørensen, J. F. L., Thomas, M., Canals, M. L., Nikolic, N., \& Hu, Y. (2006). Working conditions in international seafaring. Occupational Medicine, 56(6), 393-397.

Jeżewska, M., Babicz-Zielińska, E., Leszczyńska, I., \& Grubman, M. (2009). Promotion of healthy nutrition of seafarers. International Maritime Health, 60(1-2), 4850.

Jeżewska, M., Leszczynska, I., \& Jaremin, B. (2006). Work-related stress at sea: Self estimation by maritime students and officers. International Maritime Health, 57(1-4), 66-75.

Juozulynas, A., Sąlyga, J., Malakauskiene, R., \& Lukšiene, A. (2007). Physical and psychological dimensions of 
health-related quality of life among Lithuanian seamen. Acta Medica Lituanica, 14(1), 50-53.

Kaerlev, L., Hansen, J., Hansen, H. L., \& Nielsen, P. S. (2005). Cancer incidence among Danish seafarers: a population based cohort study. Occupational and Environmental Medicine, 62(11), 761-765.

Karasek, R. A. (1979). Job demands, job decision latitude, and mental strain: Implications for job redesign. Administrative Science Quarterly, 24(2), 285-308.

Karasek, R., \& Theorell, T. (1990). Healthy work: Stress, productivity, and the reconstruction of working life. New York: Basic Books.

Lazarus, R. L. (1990). Theory-based stress research. Psychological Inquiry, 1(1), 3-13.

Leszczynska, I., Ježewska, M., \& Jaremin, B. (2007). Workrelated stress at sea: Possibilities of research and measures of stress. International Maritime Health, 58(1-4), 93-102.

Lodde, B., Jegaden, D., Lucas, D., Feraud, M., Eusen, Y., \& Dewitte, J. D. (2008). Stress in seamen and non-seamen employed by the same company. International Maritime Health; 59(1-4), 53-60.

MacLachlan, M., Kavanagh, B., \& Kay, A. (2012). Maritime health: A review with suggestions for research. International Maritime Health, 63(1), 1-6.

McLaughlin, H. L. (2012). Seafarers and Seafaring. In W. K. Talley (Ed.), The Blackwell Companion to Maritime Economics (pp. 321-332). Oxford: Blackwell Publishing.

Nielsen, M. B., Bergheim, K., \& Eid, J. (2013). Relationships between work environment factors and workers' well-being in the maritime industry. International Maritime Health, 64(2), 80-88.

Oldenburg, M. (2014). Risk of cardiovascular diseases in seafarers. International Maritime Health, 65(2), 53-57.

Oldenburg, M., Baur, X., \& Schlaich, C. (2010a). Occupational Risks and Challenges of Seafaring. Journal of Occupational Health, 52(5), 249-256.

Oldenburg, M., Baur, X., \& Schlaich, C. (2010b). Cardiovascular diseases in the modern maritime industry. International Maritime Health, 62(3),101-106.

Oldenburg, M., Harth, V., \& Jensen, H.-J. (2013). Overview and prospect: Food and nutrition of seafarers on merchant ships. International Maritime Health, 64(4), 191-194.

Oldenburg, M., Jensen, H. J., Latza, U., \& Baur, X. (2007). Coronary risks among seafarers aboard German-flagged ships. International Archives of Occupational and Environmental Health, 81(6), 735-741.

Oldenburg, M., Jensen, H. J., Latza, U., \& Baur, X. (2009). Seafaring stressors aboard merchant and passenger ships. International Journal of Public Health, 54(2), 96-105.

Oldenburg, M., Jensen, H. J., Latza, U., \& Baur, X. (2010). The risk of coronary heart disease of seafarers on vessels sailing under German flag. International Maritime Health, 62(3), 123-128.

Oldenburg, M., Jensen, H. J., \& Wegner, R. (2012). Burnout syndrome in seafarers in the merchant marine service. International Archives of Occupational And Environmental Health, 86(4), 407-416.

Parkes, K. R., Carnell, S. C., \& Farmer, E. L. (2005). “Living two lives." Community, Work \& Family, 8(4), 413437.

Popkin, S. M., Morrow, S. L., Di Domenico, T. E., \& Howarth, H. D. (2008). Age is more than just a number: Implications for an aging workforce in the US transportation sector. Applied Ergonomics, 39(5), 542-549.

Pougnet, R., Pougnet, L., Loddé, B., Canals, L., Bell, S., Lucas, D., \& Dewitte, J.-D. (2014). Consumption of addictive substances in mariners. International Maritime Health, 65(4), 199-204.

Rengamani, J., \& Murugan, M. S. (2012) A study on the factors influencing the seafarers' stress. AMET International Journal of Management, 4, 44-51

Roberts, S. E. (2005). Work related mortality from gastrointestinal diseases and alcohol among seafarers employed in British merchant shipping from 1939 to 2002. International Maritime Health, 56(1-4), 29-47.

Roberts, S. E. (2008). Fatal work-related accidents in UK merchant shipping from 1919 to 2005. Occupational Medicine, 58(2), 129-137.

Roberts, S. E., \& Jaremin, B. (2010). Cardiovascular disease mortality in British merchant shipping and among British seafarers ashore in Britain. International Maritime Health, 62(3), 107-116.

Roberts, S. E., Jaremin, B., Chalasani, P., \& Rodgers, S. E. (2009). Suicides among seafarers in UK merchant shipping, 1919-2005. Occupational Medicine, 60(1), 54-61.

Roberts, S. E., \& Marlow, P. B. (2005). Traumatic work related mortality among seafarers employed in British merchant shipping, 1976-2002. Occupational and Environmental Medicine, 62(3), 172-180.

Rodríguez, J. L., Portela, R. M., \& Carrera, P. V. (2011). Legal gaps relating to labour safety and health in the maritime transport sector in Spain. International Maritime Health, 62(2), 91-97.

Rydstedt, L. W., \& Lundh, M. (2010). An Ocean of Stress? The relationship between psychosocial workload and mental strain among engine officers in the Swedish merchant fleet. International Maritime Health, 62(3), 168-175. 
Rydstedt, L. F., \& Lundh, M. (2012). Work demands are related to mental health problems for older engine room officers. International Maritime Health, 63(4), 176-180.

Saarni, H., Pentti, J., \& Pukkala, E. (2002). Cancer at sea: A case-control study among male Finnish seafarers. Occupational and Environmental Medicine, 59(9), 613-619.

Sampson, H., \& Zhao, M. (2003). Multilingual crews: Communication and the operation of ships. World Englishes, 22(1), 31-43.

Skevington, S. M., Lotfy, M., \& O’Connel, K. A. (2004). The World Health Organization's WHOQOL-BREF quality of life assessment: Psychometric properties and results of the international field trial. A report from the WHOQOL group. Quality of Life Research, 13(2), 299310.

Slišković, A. (2010). Problemi rada u smjenama [Adverse effects of shiftwork - A review]. Archives of Industrial Hygiene and Toxicology, 61(4), 465-477.

Smith, A., Allen, P. H., \& Wadsworth, E. (2006). Seafarer fatigue: The Cardiff research programme [Project Report]. MCA Research Report, Vol. 464. Cardiff: Centre for Occupational and Health Psychology, Cardiff University. Retrieved from http://orca.cf.ac.uk/48167/1/research_report_464.pdf
Szymanska, K., Jaremin, B., \& Rosik, E. (2006). Suicides among Polish seamen and fishermen during work at sea. International Maritime Health, 57(1-4), 36-45.

Tang, L. (2012). Waiting together: Seafarer-partners in cyberspace. Time \& Society, 21(2), 223-240.

Thomas, M., Sampson, H., \& Zhao, M. (2003). Finding a balance: Companies, seafarers and family life. Maritime Policy \& Management, 30(1), 59-76.

Ulven, A. J., Omdal, K. A., Herløv-Nielsen, H., Irgens, A., \& Dahl, E. (2007). Seafarers' wives and intermittent husbands social and psychological impact of a subgroup of Norwegian seafarers' work schedule on their families. International Maritime Health, 58(1-4), 115-128.

Wadsworth, E. J. K., Allen, P. H., McNamara, R. L., \& Smith, A. P. (2008). Fatigue and health in a seafaring population. Occupational Medicine, 58(3), 198-204.

Wadsworth, E. J. K., Allen, P. H., Wellens, B. T., McNamara, R. L., \& Smith, A. P. (2006). Patterns of fatigue among seafarers during a tour of duty. American Journal of Industrial Medicine, 49(10), 836-844.

Weng, J., \& Yang, D. (2015). Investigation of shipping accident injury severity and mortality. Accident Analysis \& Prevention, 76, 92-101. 
